\title{
O USO DA INTUIÇÃO NA CONSTRUÇÃO DE CENÁRIOS ESTRATÉGICOS: UMA ANÁLISE EXPLORATÓRIA
}

Priscilla Boff Ferronato

Universidade do Vale do Rio dos Sinos

priscillaferronato@gmail.com

Celso Carnos Scaletsky

Universidade do Vale do Rio dos Sinos

celsocs@unisinos.br

Resumo: O presente artigo apresenta os resultados de uma pesquisa realizada com o objetivo de buscar uma melhor compreensão do uso da intuição durante a atividade de construção de cenários. A pesquisa parte da premissa que o projeto de design é um processo de construção do conhecimento. Um tipo especial de conhecimento refere-se à construção de cenários e é caracterizado por ser um espaço para a conversação estratégica. Uma ação intuitiva, na perspectiva de Bergson (1984), ocupase do imediato, sendo que o objeto visto é, imediatamente, apreendido. Foram realizados protocolos para análise dos dados coletados durante atividades de construção de cenários. Os dados foram analisados por meio de linkográficos, em que o uso da intuição foi identificado nos movimentos de design. Para maior eficácia, os movimentos foram classificados de acordo com o tipo de ação projetual que estava sendo desempenhada durante a construção de cenários, como tomada de decisão e geração de ideia. Após o processo de identificação, tanto os movimentos de design considerados como intuitivos quanto a própria atividade de cenários em si, foram analisados e relacionados com a teoria. Os resultados encontrados demonstram que o uso da intuição na construção de cenários, relaciona-se com a capacidade dos designers em tornarem seus processos imediatos e experimentais, os quais emergem por meio de conexões associativas e holísticas. A intuição, sendo assim, é percebida como um recurso de projeto, uma fonte de informação face o desconhecido.

Palavras-chave: intuição, construção de cenários, design estratégico, linkografia.

Abstract: This paper presents the results of a master's thesis, which aimed to provide a better understanding of the use of intuition during scenario building activities. The research assumes that design projects can be considered a knowledge creation process. A special kind of knowledge refers to scenario building activities, which can be characterized as a space for strategic conversations. An intuitive action, according to Bergson's 
perspective (1984), deals with the immediate, in which the object that was seen is immediately perceived. Protocols have been conducted to analyze collected data during scenario building activities. After the collection process, data was analyzed through linkographics, in which the use of intuition was identified in design moves. Looking for greater efficiency, the design moves were classified according to a specific project action, which had been developed at a specific moment during the scenario building activity, such as ideation and decision making. After the identification process, both intuitive design moves and the scenario building activity were analyzed and associated to the theoretical study. The results shows that the use of the intuition in scenario building, relates to the ability of the designers to transform their procedures in immediate and experimental, which emerge through associative and holistic connections. Intuition, therefore, is perceived as a project resource, a source of information against the unknown.

Keywords: intuition, scenario building, strategic design, linkography.

\section{INTRODUÇÃO}

Design enquanto ato de projetar é uma atividade inerente ao ser humano. Logo, o pensamento em design faz parte da cognição humana e não requer-se nenhuma habilidade especial (CROSS, 2011). A natureza do design é caracterizada por Simon (1981) como qualquer ação relacionada ao ato de transformar uma situação existente e problemática em uma situação desejada e satisfatória. Na perspectiva de Cross (2011), contudo, o projeto de design vai além da busca de soluções para um problema - esse, na verdade, é apenas o ponto de partida em uma jornada de caráter exploratório.

A medida que o projeto desenvolve-se, existem momentos em que o designer apresenta limitado controle de uma determinada situação. São nessas fases do projeto que o designer utiliza seus conhecimentos tácitos, em que a intuição passa a desempenhar um papel fundamental. O presente artigo apresenta os resultados alcançados por uma pesquisa realizada com o objetivo de refletir sobre a forma que a intuição atua no processo de projeto, mais especificadamente, na construção de cenários de design. Durante o projeto, uma ação caracterizada como intuitiva ocupa-se do imediato. O uso da intuição envolve descobertas e a criação de conexões inesperadas. Logo, a intuição pode ser considerada o ponto de partida do conhecimento. Ressalta-se, contudo, que a intuição não se opõe a razão, raciocínio e intuição são processos cognitivos complementares.

Diferentes campos desenvolveram estudos com o propósito de melhor compreender o uso da intuição. De acordo com Schultz (1999), o campo da administração compreendeu que a lógica pura e a racionalidade não são suficientes para enfrentar a sobrecarga de informações e as incertezas. Sem abandonar a lógica e a razão, os administradores retornam a uma forma capaz de dominar a incerteza: a intuição.

No design, é importante melhor compreender o uso da intuição e sua relação com métodos de projeto. Badke-Schaub e Eris (2014), ao buscarem uma abordagem 
teórica que explicasse a ocorrência do uso da intuição pelo designer, perceberam que historicamente a metodologia de design foi desenvolvida como uma resposta para abordagens intuitivas, a partir do pressuposto de que a intuição geralmente envolve escolhas arbitrais e subjetivas. Entretanto, conforme comentado, os designers utilizam diferentes estratégias, as quais vão além dos métodos estruturados para alcançar novas ideias e soluções. Dessa forma, a metodologia de design parece ignorar a intuição, como sendo parte elementar do pensamento e da ação do designer.

Esta pesquisa procurou investigar o uso da intuição no processo de projeto, particularmente na construção de cenários de design. Cenários são compreendidos como espaços de conversação nos quais constrói-se mundos futuros. Buscou-se relacionar diversas visões de cenários, da sua origem no planejamento estratégico (VAN DER HEIDJEN, 2009), passando pela proposta de cenários orientados ao design (MANZINI; JÉGOU, 2003) chegando a proposta de projetos por cenários (REYES, 2015).

\section{INTUIÇÃO E DESIGN}

A presente pesquisa baseou-se no estudo de Bergson (1984), que sugere que pensar intuitivamente significa pensar em longo prazo. Para o autor a mudança é a essência da intuição, a qual é obstinada pela mobilidade, pelo insólito, pelo efêmero. Intuição significa, primeiramente, a consciência imediata. Trata-se de uma visão que quase não se distingue do objeto visto. Assim, a intuição define-se enquanto a reconciliação com o imediato. Deleuze (1999, p. 23), ao interpretar a obra de Bergson, salienta que a intuição é "[...] sobretudo o movimento pelo qual saímos de nossa própria duração, o movimento pelo qual nós nos servimos de nossa duração para afirmar e reconhecer imediatamente a existência de outras durações acima ou abaixo de nós".

Bergson (1984) restringiu o pensamento racional apenas à capacidade de oferecer novas decisões, em contrapartida, o pensamento intuitivo, não cria a partir de componentes conhecidos, mas mediante pontos de vista muito diversificados, complementares e não equivalentes. Em relação a esta perspectiva é que o autor chamou a atenção, há quase um século, para a importância do pensamento holístico e de uma capacidade perceptiva alargada para o processo criativo. Bergson (p. 178) afirma ainda que o conhecimento absoluto caracteriza-se pela "ação de entrar no objeto", apreendê-lo, captá-lo "por dentro, nele mesmo, em si". Para tanto, usa o termo simpatia para expressar esta reação: "Chamamos aqui intuição a simpatia pela qual nos transportamos para o interior de um objeto para coincidir com o que ele tem de único e, consequentemente, de inexprimível" (BERGSON, 1984, p. 181).

Conforme mencionado anteriormente, parte-se do pressuposto que a melhor compreensão do papel da intuição no projeto torna possível inserir aos métodos existentes, estratégias capazes de favorecer seu uso, quando o designer lida com momentos de incerteza, em que irá utilizar seus conhecimentos tácitos. A intuição, um dos componentes da dimensão tácita do conhecimento, é que permite os indivíduos tomarem decisões nesses momentos.

De acordo com Zurlo (2010), o designer é capaz de interpretar a complexidade, capturando dela estruturas de sentido, indicando caminhos e tornando-os visíveis. A leitura e a tradução desses sinais são de extrema utilidade para a criação de estratégias organizacionais, as quais supõem-se estarem associadas à dimensão 
intuitiva dos designers - seja de forma a influenciar o processo decisório ou como geradora de novas ideias.

Uma das formas de se traduzir estes sinais é por meio da construção de cenários. Os cenários projetuais são construídos a partir da leitura qualitativa dos sinais da contemporaneidade, os quais podem ser capazes de moldar o futuro (MANZINI; JÉGOU, 2003).

$\mathrm{Na}$ visão do planejamento estratégico, a construção de cenários auxilia as organizações na tomada de decisão, sendo uma possível forma de controle, ao se encontrar face à situações desconhecidas. A prática de construção de cenários pode ser considerada, na perspectiva de Van der Heidjen (2009), um processo de conversação estratégica. Dessa forma, esta conversação é influenciada diretamente pela forma como as pessoas veem o mundo e é, também, capaz de proporcionar a ampliação dos modelos mentais, que conduzem às descobertas.

No âmbito do design, os cenários podem ser utilizados para representar visualmente determinada intenção projetual (CAUTELA, 2007; CELASCHI; DESERTI, 2007; MANZINI; JÉGOU, 2003; ZURLO, 2010). Meroni (2008) afirma que os cenários são uma narrativa visual, textual, visões compartilháveis que traduzem informações e intuições em conhecimento perceptível. De acordo com esta perspectiva, projeta-se cenários, e este ato pode ser confundido com o próprio "projetar". Os cenários são espaços onde os diversos atores irão "atuar" na construção de algo desejado, que modifique a situação existente. Os atores não são "seres" externos, eles interagem com os cenários e são por ele modificados.

Uma visão sutilmente diferente ligada ao conceito de cenários é proposta por Reyes (2015). Na visão do autor, o uso da expressão "projetar por cenários" é mais apropriado, visto que "[...] o projeto por cenários rompe por dentro, permitindo que o processo se abra para outras alternativas" (2015, p. 186). Assim, reforçam-se os cenários como um elemento que permite e favorece conversações. Essa é a visão, que mais aproxima-se do conceito de cenários utilizado por este trabalho.

Projetar por cenários muitas vezes é confundido com métodos e ferramentas. Fato este, que não é necessariamente um equívoco. É possível compreender a construção como uma maneira de raciocinar e construir conhecimentos. Essa maneira de raciocinar poderá ser traduzida por ferramentas e métodos a ela adequados. Como observa Godet (2006), ferramentas não substituem os pensamentos e não devem bloquear a liberdade de escolha. Liberdade de ousar, de transgredir o presente, de exercitar um olhar criativo e ultrapassar a barreira das convenções em direção às muitas possibilidades que o futuro reserva. Assim, um dos maiores desafios da pesquisa aqui apresentada, deu-se em buscar uma maior compreensão sobre a utilização da intuição pelo designer durante a construção de cenários. Dessa forma, a observação desse fenômeno em uma pesquisa de campo mostrou-se necessária.

\section{MÉTODO}

O design, por meio do processo de projeto, é capaz de englobar diferentes habilidades cognitivas como a criatividade, capacidade de síntese e de resolução de problemas. Suas atividades assumem um caráter situacional, o que dificulta a obtenção de respostas definitivas em relação ao fenômeno a ser investigado. A presente pesquisa, dessa forma, caracterizou-se por uma abordagem exploratória e 
qualitativa e que utilizou a técnica de análise de protocolo como principal recurso metodológico.

Cross, Christiaans e Dorst (1996) consideram a análise de protocolo um dos principais métodos de análise utilizado pelos pesquisadores da área do design, para a obtenção de informações relativas ao comportamento cognitivo dos designers durante o processo de projeto. Essa pesquisa utilizou de forma complementar o protocolo retrospectivo e o simultâneo. No protocolo retrospectivo, os participantes foram convidados a relembrar suas atividades de forma a revelar informações a respeito da produção de ideias e tomadas de decisões. O protocolo simultâneo buscou o rastreamento do processo de compreensão do problema e de definição do projeto. Por meio da técnica think aloud (ERICSSON; SIMON, 1993) os participantes verbalizavam seus pensamentos, de modo simultâneo, com a sua execução da tarefa. Os registros dos dois protocolos foram codificados e analisados posteriormente por meio da linkografia.

O processo de construção de um linkográfico baseia-se em identificar movimentos de design e suas relações - links (GOLDSCHMIDT, 2014). Um movimento de design é qualquer tipo de ação, seja esta uma fala ou uma determinada atitude do designer, que possa modificar uma dada situação de projeto. Considerando-se o tempo transcorrido entre um movimento e outro, bem como os possíveis links criados entre os mesmos, pode-se identificar o uso da intuição do designer em determinados instantes projetuais.

A atividade de cenários, proposta para a coleta de dados, dividiu-se em duas grandes etapas, descritas a seguir. Os participantes selecionados deveriam identificar e projetar um cenário futuro, o qual respondesse a um determinado problema de projeto. Assim, foi proposta uma temática abrangente e complexa, em que os participantes deveriam identificar e projetar o futuro da educação escolar de crianças e jovens. Foram selecionados designers profissionais e em processo de formação acadêmica, os quais foram organizados em duplas, com diferentes níveis de experiência.

A primeira fase da atividade proposta dizia respeito à identificação das forças motrizes, forças que podem guiar a projetação de cenários futuros. Sabe-se que o modo mais usual de representá-las é por meio do gráfico de polaridades. Contudo, optou-se pela prototipação das forças motrizes, utilizando um modelo desenvolvido com a finalidade de representar conversas tridimensionalmente. Essa pesquisa foi a primeira a utilizar o modelo para projetar cenários, sendo um processo de descoberta tanto para os designers quanto para os pesquisadores envolvidos no projeto. $O$ modelo utilizado é o resultado de uma pesquisa com apoio da CAPES e CNPq entre a Universidade do Vale do Rio dos Sinos e Institute of Design do Illinois Institute of Technology. O modelo físico é composto por um conjunto de placas transparentes quadrados, retângulos e triângulos - feitas de acrílico e com diferentes cores. As placas possuem ímãs em suas arestas, que permitem serem conectadas entre si. Acredita-se que a interação entre os diversos atores com este modelo possa gerar novas interpretações às conversações. A figura 1 apresenta o resultado desta fase da pesquisa, com a prototipagem das forças motrizes. 


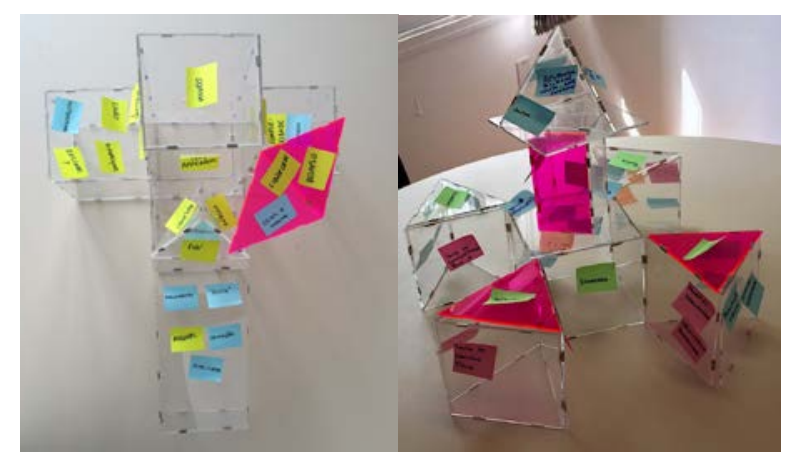

Figura 1 - Prototipagem das forças motrizes.

Fonte: Elaborado pelos autores, com base na pesquisa realizada.

A segunda etapa referia-se à representação física do cenário futuro. Dessa forma, foram disponibilizados diversos materiais, como cartolina, isopor, canetas, papéis, massa de modelar, business origamis, layouts para o desenvolvimento de storytelling e personas. Geralmente, os cenários são representados por meio de moodboards. Entretanto, ressalta-se que foi solicitado aos participantes que não utilizassem o que é usual nas atividades de construção de cenários, justamente para incentivar o uso da intuição. Ao final da etapa de representação, os participantes apresentaram o cenário futuro e, também, relataram o processo de como chegaram até a representação proposta. $O$ vídeo resultante destas duas etapas foi segmentado e analisado por meio dos linkográficos. Os principais resultados encontrados são descritos a seguir.

\section{ANÁLISE}

A intuição foi analisada em relação a três diferentes aspectos e momentos do processo de construção de cenários: níveis de expertise dos participantes, momentos de tomada de decisão e momentos de geração de ideias. De forma a analisar especificamente os processos de geração de ideia e tomada de decisão, estes momentos foram identificados nos linkográficos, sendo posteriormente analisados em relação aos links encontrados, conforme detalhamento da figura 2.

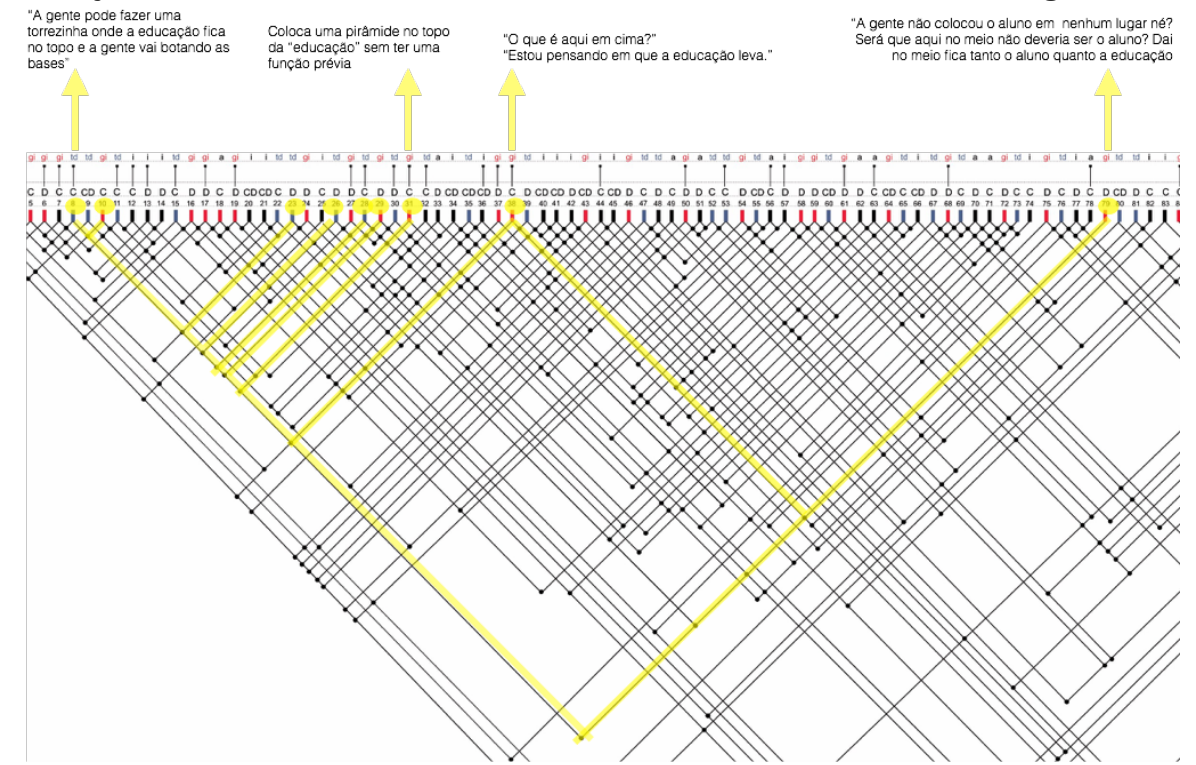

Figura 2: Detalhamento do linkográfico para a identificação de diferentes momentos projetuais. Fonte: Elaborado pelos autores, com base na pesquisa realizada. 
A tabela 1 traz uma síntese quantitativa dos movimentos de design, identificados em cada um dos linkográficos. É apresentado, primeiramente, a quantidade de movimentos de design e, também, o percentual de uso da intuição em cada categoria de movimento (por exemplo, o participante A teve 15 movimentos de geração de ideia e utilizou a intuição em $60 \%$ destes movimentos). Ressalta-se ainda, que o participante $A$ e $B$ são pertencentes à dupla 1 e os participantes $C$ e $D$ pertencentes à dupla 2 .

Tabela 1 - Síntese quantitativa dos linkográficos.

\begin{tabular}{lcccc}
\hline & Participante A & Participante B & Participante C & Participante D \\
\hline Geração de Ideia & $15 \mid 60 \%$ & $39 \mid 59 \%$ & $14 \mid 50 \%$ & $31 \mid 42 \%$ \\
Tomada de Decisão & $17 \mid 53 \%$ & $21 \mid 28 \%$ & $24 \mid 46 \%$ & $10 \mid 10 \%$ \\
Total de Movimentos de Design & $42 \mid 50 \%$ & $75 \mid 43 \%$ & $57 \mid 42 \%$ & $53 \mid 30 \%$ \\
\hline
\end{tabular}

Fonte: Elaborado pelos autores, com base na pesquisa realizada.

Em relação aos movimentos caracterizados como de geração de ideia, ao verificar sua localização e disposição espacial nos linkográficos, percebe-se que estes apresentaram-se principalmente nas fases iniciais das diferentes atividades desempenhas durante o processo de projetar cenários, como a identificação das forças motrizes, utilização do modelo, representação do cenário futuro, dentre outras. É possível relacionar o processo de ideação a uma fase de exploração e geração de alternativas, em que o erro é mais fácil de ser articulado, uma forma de pensamento divergente.

A pouca variação percentual do uso da intuição nos movimentos de geração de ideia, em relação aos participantes da pesquisa $(60 \%, 59 \%, 50 \%, 42 \%$, conforme apresentado na tabela acima), ratifica que a mesma, ao associar-se a ações de exploração do projeto e de tolerância ao erro, é capaz de criar um espaço propício ao uso da intuição. Portanto, as diferentes características intrínsecas a cada participante, como por exemplo, o diferente nível de expertise em design, não são fatores que se relacionam ao uso ou não da intuição, durante o processo de ideação.

Alguns processos comuns aos participantes foram identificados como atributos do uso da intuição para a geração de ideias, são eles: a apreensão imediata de um fato, o uso de experiências pessoais e o processo de conhecer na ação em função da descoberta. Esses processos foram perceptíveis em diferentes movimentos de design, como por exemplo, quando um participante teve a ideia de colar um post-it em uma forma geométrica que montou com o modelo disponibilizado, dando início posteriormente ao processo de identificação das forças motrizes. Nesse momento, 0 participante foi capaz de direcionar o processo de modelagem das forças motrizes, iniciando a atividade concomitantemente com a exploração do próprio modelo, em um processo de conhecer na ação. A sua falta de conhecimento específico, em relação tanto ao uso do modelo quanto a própria atividade de construção de cenários em si, pode desencadear o processo de descoberta.

Por meio da análise dos linkográficos construídos constatou-se que os movimentos de design, caracterizados como de geração de ideia, foram os que deram origem ao maior número de links. Fato este, que independe se as ideias apresentadas foram ou não relacionadas posteriormente a movimentos de tomada de decisão. Logo, percebe-se que, muitos dos movimentos de geração de ideia, relacionam-se a 
movimentos de reflexão, tanto sobre algo pontual quanto sobre o próprio projeto em si, originando assim a maior quantidade de links. Por exemplo, um participante ao falar sobre sua ideia de representação do cenário futuro, evidencia a análise que faz sobre sua própria ideia, antes imediata e intuitiva: "A gente pode fazer uma maquete dessa sala de aula [...] mas acho que é meio bobo, a gente vai entrar na história [...] temos que fazer algo impensável". O participante teve um movimento de geração de ideia. Contudo, ao invés de implementar imediatamente a ideia, de criar uma maquete em um processo de conhecer na ação, gera um movimento de reflexão, prevendo que, caso a implementasse, o resultado seria "bobo". Em movimentos posteriores, o participante volta a refletir sobre a forma de representar o cenário futuro, como quando afirma: "Talvez poderíamos fazer uma obra de arte para representar [...] algo antes nunca imaginado".

Assim, a intuição pode ser entendida como um gatilho à geração de ideias. Em relação ao universo pesquisado, os movimentos de ideação são caracterizados como um processo de construção do novo, capaz de direcionar e qualificar o processo de projeto, devido à formação de novos links nos linkográficos. Quanto mais ideias são geradas no decorrer do projeto maior é o espaço para a reflexão do mesmo, consequentemente, facilita-se o processo de tomada de decisões.

Em relação aos movimentos de tomada de decisão, é possível associá-los a uma forma de pensamento convergente - de fazer escolhas. A dualidade no uso do raciocínio e da intuição é inerente a todos os indivíduos. Observou-se que, em ambas as duplas, os designers com menos experiência profissional usaram com mais frequência da intuição no processo de tomada de decisão. Na dupla 1, o participante A usou a intuição em $53 \%$ dos movimentos de tomada de decisão, enquanto que o participante B usou em $28 \%$ dos movimentos. Na dupla 2, o participante $\mathrm{C}$ usou a intuição em $46 \%$ dos movimentos de tomada de decisão, enquanto que o participante D usou em apenas $10 \%$ dos movimentos.

Uma decisão atribuída à intuição, de acordo com a própria definição de intuição por Bergson (1984), é aquela em que trata do imediato. Este fato pode ser percebido em diferentes movimentos de tomada de decisão, como por exemplo, quando um participante vê a forma retangular que sua dupla construiu e afirma: " $A$ gente pode fazer essa torrezinha, onde educação fica no topo e a gente vai botando as bases". A partir desse movimento o participante decide tanto a estrutura a ser construída com o modelo, quanto como será realizada a categorização das palavras, organizando-as no modelo na forma de pilares para dar suporte a "torre", que representa a educação.

Entretanto, percebe-se que o uso da intuição foi relacionado a outros aspectos do processo de tomada de decisões, além da atribuição do seu uso a uma decisão imediata e instantânea. Conforme mencionado anteriormente, os participantes considerados menos experientes, utilizaram mais da intuição para as diferentes tomadas de decisão projetual. Em uma análise retroativa dessas decisões, percebeu-se que a intuição foi utilizada como um recurso de projeto, capaz de facilitar e justificar o processo decisório. Em uma sequência de movimentos de design $(95,97,99,112,114)$ discutiu-se a relação de determinado participante com o uso da massa de modelar (disponibilizada para a representação dos cenários) e o fato deste não misturar as cores devido sua experiência pessoal. No movimento 97, depois de sua dupla tê-lo convencido a misturar as massas de modelar, o participante afirma: "Tá, eu vou ver 
qual cor combina". A escolha por combinar as cores se deu de forma completamente imediata, sendo relacionada à sua experiência pessoal, em como foi ensinado a manusear o material. Em complemento, no movimento 114, justifica a sua decisão: "É que tu achas que eu ganhava um pacote de massinha de modelar sempre? Era um pacotinho só...".

Ao relacionar a presente constatação aos estudos Dreyfus (1980), sobre o modelo de aquisição de habilidades, é possível perceber divergências entre o observado e o proposto pela teoria. As divergências encontram-se relacionadas a partir das distinções dos níveis de especialização proposto pelo modelo de aquisição de habilidades, em que designers experts ao transcenderem "regras" atuam de forma mais intuitiva, baseando suas ações no seu conhecimento tácito. Enquanto que designers menos experientes são mais rígidos às "regras", tratando diferentes aspectos separadamente, mas com igual importância (DREYFUS, 1980). Entretanto, os designers são capazes de exibir simultaneamente diferentes graus de expertise em um mesmo projeto, de acordo com a atividade que estão desempenhando. Sendo assim, tendo a experiência profissional em design, como expertise e, relacionando-a ao uso da intuição, pode-se constatar que, no contexto dos grupos estudados, em diferentes situações de projeto, a expertise é vista como uma variável situacional. Por conseguinte, os níveis de expertise não podem ser considerados uma forma eficaz de caracterizar um designer, quando realizada de forma generalista.

A construção de cenários, por ocupar-se de incertezas futuras, faz com que o designer lide com incertezas também em relação ao próprio processo de projeto. Por conseguinte, a construção de cenários, torna-se uma atividade capaz de explorar e construir conhecimentos na ação. Em relação ao processo de conhecer na ação, Schön (2000) afirma que sendo o design um processo criativo, no qual o designer passa a ver e a fazer coisas de uma nova maneira, no decorrer do processo, é possível afirmar que cada projeto é visto como único.

Ao analisar o uso da intuição para a construção de cenários, inicialmente percebeu-se que esta atividade pode ser um espaço facilitador para a explicitação do conhecimento tácito dos designers. Fato este, atribuído à própria construção de cenários enquanto um espaço para a conversação estratégica (MERONI, 2008) de natureza colaborativa, na qual torna-se necessário que os participantes explicitem o seu conhecimento pessoal. Ressalta-se que nessa pesquisa, a conversão do conhecimento tácito em conhecimento explícito realizou-se tanto em movimentos de geração de ideias quanto em movimentos de tomada de decisão. Entretanto, conforme observado por meio da análise dos dados coletados, o uso de analogias, metáforas e o compartilhamento de histórias e experiências anteriores, foi percebido de forma mais acentuada pelos participantes com menos experiência profissional, como uma forma de justificar suas ações. Como por exemplo, durante a definição de um conceito para a construção dos cenários relacionados a forças motrizes identificadas referente a integração social e o saber da terceira idade o participante explicita a sua decisão por meio de um exemplo prático ao conceito criado: "Eu vi um caso aqui em Porto Alegre, em que os velhinhos de um asilo foram jurados de um concurso de skate. Os skatistas foram lá e se apresentaram para eles [...] ser jurado é proporcionar novas experiências...". O participante explicita o seu conhecimento até então tácito. Por conseguinte, é visível que à medida que a transformação do conhecimento se faz necessária, há demasiada presença do conhecimento tácito. 
Percebeu-se, também, que devido à transformação do conhecimento tácito em explícito ser uma forma de expressar o que não pode ser expresso verbalmente, a utilização de métodos e ferramentas, que possibilitem um espaço para a conversação, torna-se relevante e essencial em termos de facilitação, acessibilidade e compartilhamento. A presente constatação ocorreu tanto com o uso dos post-its, quanto com o uso do modelo. Durante a identificação das forças motrizes, por exemplo, um participante, iniciou a atividade escrevendo palavras chaves nos post-its. Essa é uma ação que lhe é usual, por conseguinte, ocorre de forma imediata e não planejada. Este participante possui experiência profissional em projetos de design e Ihe é usual iniciar com um brainstorming ou com anotações de conceitos em post-its, facilitando o processo de organizar e possibilitando assim a explicação de suas ideias para o outro participante.

Ao analisar o uso de instrumentos que facilitassem o processo de construção de cenários, percebe-se que o modelo disponibilizado para a identificação das forças motrizes, por meio de criação de representações físicas e tridimensionais possibilitou a percepção de novas conexões entre os conceitos trabalhados. O modelo passa, então, a ser um suporte à intuição, à medida que permite uma nova forma de percepção, a qual é imediata e colaborativa. Por exemplo, durante o processo de revisão e reflexão sobre os conceitos trabalhados durante a representação das forcas motrizes, um participante afirma: "Tem a tecnologia, a liberdade está aqui, o reaprender está aqui, o touch está aqui, este está aqui em cima" e tenta sobrepor um post-it ao outro. Percebe-se que o participante, em uma tentativa de buscar novas ideias, revê os conceitos trabalhados. Entretanto, é a ação de sobrepor os post-its que gera ideias para a construção de cenários, algo que até então não havia sido explorado com a forma usual de se trabalhar, em planos bidimensionais (moodbords).

O próprio aspecto tridimensional permite que as interpretações, além de serem compartilhadas e criadas de forma colaborativa, possam ser interpretadas, em decorrência do processo de deslocamento do campo de visão do participante, permitindo uma nova forma de entendimento. Portanto, não trata-se apenas de "colocar-se no lugar do outro", mas de "enxergar com os olhos do outro". O uso do modelo influenciou diretamente o processo de geração de ideias e tomada de decisões, como um meio capaz de permitir a conexão de conceitos que estavam sendo trabalhados de maneira isolada, gerando assim novas interpretações sobre o projeto. A presente constatação pode ser observada, por exemplo, quando um participante monta uma peça que se assemelha a uma asa delta e afirma: "Olha, é como a liberdade". Em um movimento subsequente continua a refletir: "A gente poderia colocar lá em cima, como desafio, mais perigo". Percebe-se que o participante continua a relacionar com conceitos que haviam sido trabalhados anteriormente, durante os movimentos iniciais sobre quais seriam as forças motrizes de forma generalizada, mas que, até então (cerca de 40 movimentos de design depois), não se relacionava com a temática trabalhada. Por fim, o participante conclui: "Nosso objetivo agora é buscar formas nunca antes pensadas". O conceito de liberdade passa ser oriundo ao significado da forma de asa delta. Após esta definição conceitual, o participante ainda reflete e afirma que sua dupla deveria se libertar de sua decisão sobre a representação do cenário, que deveria ser como o próprio projeto e fazer coisas que não faria anteriormente.

Novas conexões e interpretações são consequências não somente do uso do 
modelo, mas a uma visão holística da situação, a qual associa-se ao uso da intuição. A visão holística foi explorada por Bergson (1984), sendo atribuída ao uso da intuição. 0 autor ressaltou a importância da visão holística e da capacidade perceptiva alargada para o processo criativo. Em decorrência da projeção no tempo durante a o processo de projeto, a visão holística faz-se necessária, pois é essencial para que novas conexões sejam percebidas.

Dentro do universo pesquisado, ressalta-se ainda, que os participantes mais intuitivos desempenharam um papel de "líder de projeto", independentemente do seu nível de expertise. Ou seja, estes participantes conduziram o andamento do projeto, de forma tanto a direcionar, bem como, a incentivar as ações do outro participante. Por conseguinte, os atributos associados ao uso da intuição, dentro do universo pesquisado podem ser sintetizados em relação à utilização e adaptação de experiências passadas a situações atuais, o uso da visão holística possibilitando novas percepções e interpretações, a busca do novo e a capacidade de adentrar em uma dada situação e apreendê-la de forma imediata.

\section{CONSIDERAÇÕES FINAIS}

O processo de projeto pode ser considerado um processo de construção de conhecimento, no qual todo conhecimento é pessoal e reflete a própria experiência do indivíduo. A experiência pessoal, logo, é um fator condicionante para construção do conhecimento (POLANYI, 1966). O design, por sua natureza criativa, possibilita a conversação reflexiva do designer com os materiais de uma situação, proporcionando novas descobertas, significados, invenções (SCHÖN, 2000). A construção de cenários pode ser uma forma de reflexão, à medida que torna-se possível projetar-se no tempo e usar a intuição como forma de criar memórias futuras, para refletir sobre o próprio desenvolver do processo de projeto.

A partir da observação, por meio dos movimentos de design identificados nos linkográficos, ficou claro que o designer utiliza sua intuição durante todo o decorrer do projeto, sendo impossível dissociá-la da sua experiência pessoal e do seu processo de construção do conhecimento. A intuição é intrínseca ao indivíduo e sua análise deve partir do mesmo, relacionando-se à forma como esta é ativada e como pode-se proceder para melhorar o seu uso. Logo, o uso da intuição é percebido como um recurso de projeto, uma fonte de informação face o desconhecido.

Instrumentos que facilitam a interpretação e o entendimento do ponto de vista do outro, como o modelo físico disponibilizado, auxiliam a atividade de construção de cenários. $O$ processo, por conseguinte, torna-se mais colaborativo e participativo. 0 modelo, além de desencadear o uso da intuição, é um complemento à mesma, devido a forma diferenciada que atua na construção de uma determinada interpretação. Haja vista, que permite ao participante deslocar seu campo de visão em direção às interpretações, as quais são compartilhadas e co-criadas.

Essa pesquisa não esgotou os temas aqui trabalhados, ao contrário, possibilitou o surgimento de novas questões a serem exploradas. Pesquisas relacionadas ao uso da intuição do designer podem desenvolver-se a partir da premissa que o designer é capaz de apresentar diferentes níveis de expertise durante o processo de projeto, bem como um estudo mais amplo de diferentes instrumentos de design capazes de desencadear o uso da intuição, como o modelo aqui utilizado. 


\section{REFERÊNCIAS}

BADKE-SCHAUBE, P.; ERIS, O. A theoretical approach to intuition in design: does design methodology need to account for unconscious processes? In: CHAKRABATI, A.; BLESSING, L. (Ed.). An anthology of theories and models of design. London: SpringerVerlag, 2014. p. 353-370.

BERGSON, H. O pensamento e o movente. São Paulo: Abril Cultural, 1984. (Coleção os pensadores).

BROWN, T. Design thinking: uma metodologia ponderosa para decretar o fim das velhas ideias. Rio de Janeiro: Elsevier, 2010.

CAUTELA, C. Strumenti di design management. Milão: Tipomonza, 2007.

CELASCHI, F; DESERTI, A. Design e innovazione: strumenti e pratiche per la ricerca applicata. Milão: Carocci, 2007.

CROSS, N. Design ability. In: CROSS, Nigel. Design thinking: understanding how designers think and work. New York: BERG, 2011. p. 3-30.

CROSS, N.; CHRISTIAANS, H.; DORST, K. (Ed). Analysing design activity. Chinchester: John Wiley, 1996.

DELEUZE, G. O bergsonismo. Rio de Janeiro: Editora 34, 1999.

DREYFUS, H.; DREYFUS, S. A five stage model of the mental activities involved in skill acquisition. Operations Research Center. University of Berkeley, 1980.

DORST, K. The problem of design problems. Design Thinking Research Symposium. Sydney: Sydney University of Technology, 2003. Documento em PDF.

GODET, M. Creating Futures: scenario planning as a strategic management tool. Paris: Economica, 2006.

GOLDSCHMIDT, G. Linkography: unfolding the design process. Cambridge: MIT Press, 2014.

MANZINI, E.; JÉGOU, F. Sustainable Everyday: Scenarios of urban life. Milan: Edizione Ambiente, 2003.

MERONI, A. Strategic design: where we are now? Reflextions around the foundations of a recent discipline. Strategic Design Research Journal, Porto Alegre, v. 1, n.1, p. 3242, 2008. Documento em PDF.

POLANYI, M. The Tacit Dimension. London: Routledge and Kegan Paul, 1966.

REYES, P. Projeto por Cenários. Porto Alegre: Sulina, 2015.

SIMON, H. A. As ciências do artificial. Coimbra: Armênio Amado, 1981.

SCHÖN, D. Educando o profissional reflexivo: um novo design para o ensino e a aprendizagem. Porto Alegre: Artmed Editora, 2000.

SCHULTZ, R. Sabedoria e Intuição. São Paulo: Cultrix/Amana, 1999.

VAN DER HEIDJEN, K. Planejamento por cenários: a arte da conversação estratégica. Porto Alegre: Bookman, 2009 
ZURLO, F. Design Strategico. In: XXI Secolo, v. IV, Gli spazi e le arti. Roma: Enciclopedia Treccani. 2010. Disponível em:

<http://www.treccani.it/enciclopedia/designstrategico_(XXIecolo)>. Acesso em 15 de fev. 2015. 